\title{
Race for Dungeness crab influences processing, markets
}

\author{
Steven C. Hackett \\ Christopher M. Dewees \\ Matthew J. Krachey \\ $\nabla$
}

recent decades the California Dungeness crab fishery has experienced a race for crabs, or derby, where approximately $80 \%$ to $90 \%$ of annual seasonal landings occur between late November and the end of December. Some processors have responded by developing large-scale processing and freezing capacity that can accommodate the pulse of crab landings and be used for processing other fish species at other times of the year. The combination of large-scale processing and declines in the groundfish and salmon fisheries has resulted in a more consolidated processing industry structure that features a small number of large processing firms.

Baseline economic information was collected on this processing sector in California for two Dungeness crab fishing seasons, 1999-2000 and 2000-2001 (Hackett et al. 2003). Our research methodology involved the use of confidential fish-ticket data from the California Department of Fish and Game, and interviews with key informants at six processing firms. These firms, located in California and southern Oregon, purchased $60 \%$ of the crab landed in California in 1999-2000. We found that:

- The estimated average wholesale price of various Dungeness crab products (adjusted for yield rates from the live crab) in 1999-2000 was approximately $\$ 3$ per pound.

- The estimated value added by processors ranged from $\$ 8.45$ million to $\$ 8.83$ million. Value added by processors is measured as processed-crab sales revenue less the cost of crab purchased from fishermen, whereas value added by fishermen is measured as revenue received by fishermen for selling crab to processors.

- The estimated value added by processors ranged from $47.5 \%$ to nearly $50 \%$ of that added by crab fishermen.

- The value added by fresh and live products (based on yield-adjusted prices expressed as a percentage of the ex-vessel value) was generally less than that of the frozen and picked-meat products.

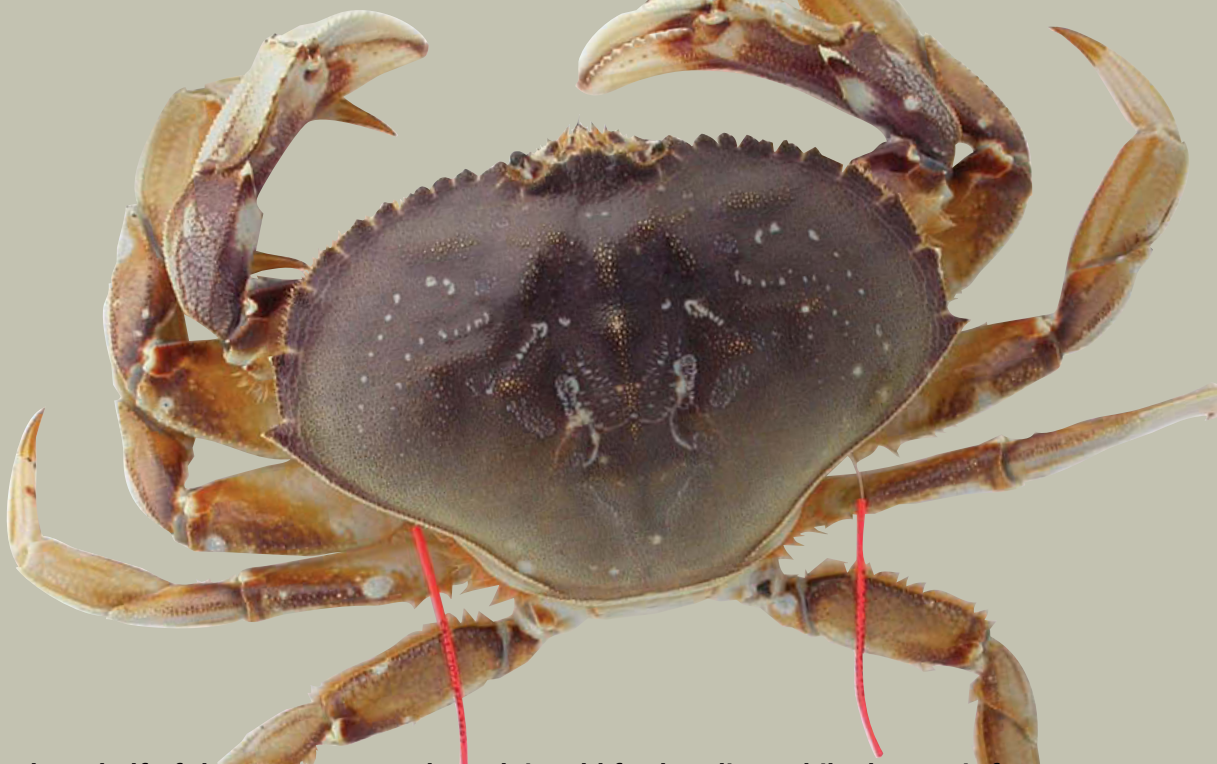

About half of the Dungeness crab catch is sold fresh or live, while the rest is frozen or processed into picked meat. This crab has two red tags; cooperating commercial fishermen return the tags so that researchers can estimate crab movements and collect other data.

Prices. If fresh and live product are perceived by consumers as possessing superior quality to that of the frozen product (much of the picked meat originates from the secondary processing of previously frozen crab), then presumably this would be manifested in higher prices per pound for the fresh and live product, especially if the pulse of landings suppresses this product. In fact, our analysis suggests that this was not the case - the frozen and picked meat featured higher yield-adjusted prices per pound than those of fresh and live product. Our estimates indicate that only about one-half of the Dungeness crab landed in California was processed into fresh or live product during the 19992000 and 2000-2001 seasons.

Value of picked meat. The superior yield-adjusted price for picked-meat product could be explained by the notion that many final consumers (such as diners at restaurants and on cruise ships) value convenience over freshness, since picking meat from a Dungeness crab is a somewhat laborious task. In fact, our estimates for percentage value added in 1999-2000 are consistent with the picked-meat product having the highest yield-adjusted value in the marketplace (though this was somewhat less evident in the 2000-2001 estimates). Processors in our interviews noted the importance of maintaining restaurant, cruise ship and other food-service accounts that serve as key market channels for picked meat. The importance of maintaining these picked-meat market channels is indicated by trends in the estimated share of total statewide Dungeness crab landings going into the picked-meat product. The percentage of crab processed into a picked-meat product generally increased in 2001, when landings had decreased, indicating the importance of protecting market channels for picked meat.

Employment. Hackett et al. (2003) were only able to get sufficient information on employment and capital stock in Dungeness crab processing from surveys to develop industry-wide estimates for the 2000-2001 season. Estimated total peak crab-processing employment in 2000-2001 ranged between 485 and 552 people during the weeks when the pulse of Dungeness crab landings is being processed. In contrast, off-peak "year-round" industry-wide employment (mostly picking lines) was estimated to range between 88 and 142 people.

Luxury/special occasion food. Most of the processors surveyed consider Dungeness crab to be a seasonal or a luxury food associated with celebratory events, with peak consumption of fresh crab occurring between Thanksgiving and New Years Day. Processors noted difficulty in moving fresh crab after late January (Super Bowl weekend). Because fresh or live crab is difficult for consumers to locate after late January, it is impossible to judge whether consumer demand would increase if it were available for longer. 
There is certainly substantial demand for the live product during the holiday season when it is available.

Frozen product. The large processors mentioned that target inventory levels for frozen crab are usually set prior to the season based on existing inventory and projected consumer demand. Processors base their demand estimates on overall economic indicators (economic growth, consumer confidence) and the price and availability of substitutes. Key substitutes were reported to be Dungeness crab products out of Washington, Oregon and British Columbia; snow crab products; and more generally, other seafood and meat products. As the season begins and it becomes clear that target inventory levels will be reached, production shifts to include fresh and live product. Processors noted that fresh product is easier to unload quickly. In years with low landings, large processors focus most of their production on frozen products, leaving more of the fresh and live market to smaller processors.

New markets. The processors interviewed reported considerable difficulty in moving large quantities of fresh crab product outside of the region due to the cyclical nature of the fishery. In years with large landings, the industry is able to develop new markets, such as East Coast restaurants. These processors report high product satisfaction in these new markets. But when years with small landings come along, processors report that rising ex-vessel prices put upward pressure on fresh product prices, and out-of-region markets are more price-sensitive than those within the region due to reduced product identity. Processors claim that this price sensitivity effectively eliminates fresh Dungeness crab products from being regular restaurant menu items outside of the region.

David G. Hankin and Kristen Sortais contributed helpful review of this sidebar.

\section{Reference}

Hackett SC, Krachey MJ, Dewees CM, et al. 2003. An economic overview of Dungeness crab (Cancer magister) processing in California. CalCOFI Report 44:86-93.

TABLE 5. Opinions* of survey respondents on crab management tools, by vessel size category

\begin{tabular}{|c|c|c|c|}
\hline \multirow[b]{2}{*}{ Management tools } & \multicolumn{3}{|c|}{ Vessel size } \\
\hline & $\begin{array}{l}\text { Small } \\
<30 \mathrm{ft} \text {. }\end{array}$ & $\begin{array}{c}\text { Medium } \\
30 \text { to } 50 \mathrm{ft} \text {. }\end{array}$ & $\begin{array}{r}\text { Large } \\
>50 \mathrm{ft} .\end{array}$ \\
\hline Current management system & 4.3 & 4.1 & 3.9 \\
\hline One trap-limit for all size vesselst & $4.1 \S$ & $4.3 \S$ & 2.8 \\
\hline Daylight-only fishing ${ }^{\dagger}$ & $4.5 \S$ & $3.8 \S$ & 2.6 \\
\hline Transferable trap certificates & 2.8 & 2.6 & 2.6 \\
\hline Nontransferable trap certificates & 2.3 & 2.9 & 2.5 \\
\hline Trip limits & 3.1 & $2.7 \S$ & 2.1 \\
\hline Different trap limits for different-size vessels & 3.1 & 2.3 & 3.0 \\
\hline One trap-haul per day & 2.9 & 2.7 & 2.2 \\
\hline Regional/area/zonal management† & $3.3 \S \#$ & $2.7 \S$ & 1.7 \\
\hline Transferable IFQs** & 1.9 & 2.0 & 2.3 \\
\hline Nontransferable IFQs & 2.2 & 1.7 & 1.7 \\
\hline Community quotast & $2.2 \S$ & $1.7 \S$ & 1.1 \\
\hline Graduated trap limits & 1.8 & 1.7 & 1.3 \\
\hline \multicolumn{4}{|c|}{ * Scale: 5 = strongly favorable, 4 = favorable, 3 = neutral, 2 = unfavorable, 1 = strongly unfavorable. } \\
\hline \multicolumn{4}{|c|}{$\dagger$ Vessel size categories significant, Kruskal-Wallis test, $P=0.01$} \\
\hline \multicolumn{4}{|c|}{$¥$ Vessel size categories significant, Kruskal-Wallis test, $P=0.05$} \\
\hline \multicolumn{4}{|c|}{$\S$ Significantly different from large vessels, Kolmogorov-Smirnov test, $P=0.01$. } \\
\hline \multicolumn{4}{|c|}{ I Significantly different from large vessels, Kolmogorov-Smirnov test, $P=0.05$. } \\
\hline \multicolumn{4}{|c|}{ \# Significantly different from medium vessels, Kolmogorov-Smirnov test, $P=0.05$. } \\
\hline **Individual fishing quotas. & & & \\
\hline
\end{tabular}

There is widespread approval among fishermen of the current crabmanagement regulations based on traditional fishery management tools with seasons. However, when additional regulations are considered that affect fishing operations, opinions become highly polarized or negative.

Trap limits. The great increase in the number of traps fished and the accelerating pace of the fishery has led to years of discussion about whether to limit the number of traps each vessel may fish. On Sept. 23, Governor Schwarzenegger vetoed a bill that would have established a limit of 250 traps per vessel south of Point Arena, on an experimental basis. Our study showed that the majority of the fleet, with the exception of the large vessel owners, viewed trap limits favorably. Many of those survey respondents who oppose trap limits stated that they viewed it as a reallocation of crab to smaller operators. They saw this as a restriction of their business that was unjustified in terms of resource conservation.

We anticipate that trap limits would at best cap the total number of traps near current levels and prevent large increases in fishing effort. After implementation of trap limits in Maine's lobster fishery, the total number of traps fished increased (Acheson 2001). While the relatively few lobstermen above the trap limit reduced their operations, many of those under the limit increased their trap numbers toward the limit. Depending on the level set for trap limits,
California's outcome could be similar. One alternative approach would be to scale trap limits to vessel length. However, the fleet did not rank this option favorably (table 4). California should also examine the early outcomes from trap-limit systems recently implemented in Washington state. Inside Puget Sound, trap limits are set at 100 per vessel and there are six harvest regions. Along the Pacific Coast there are trap tiers ranging from 350 to 500 traps per vessel based on catch history (personal communication, L. Veneroso, Shellfish

Policy Leader, Washington Dept. of Fish and Wildlife).

If the industry wants to significantly reduce the total amount of gear in the water, additional measures that "ratchet down" the trap limit may be necessary. Some form of trap certificates, similar to those implemented in the Georgia blue crab and Florida spiny lobster fisheries (CFAC 1997; Larken and Milon 2000) might eventually need to be considered. Such a system would involve setting a total number of traps to be used by the fleet and issuing certificates (one per trap) to be placed on each trap by fishermen. The number of certificates could be reduced each year until the desired fleet-wide total is reached. Certificate transferability and geographic specificity could also be included.

Some form of trap limits is the alternative management tool most likely to be implemented because of the high level of approval among fishermen. Trap 

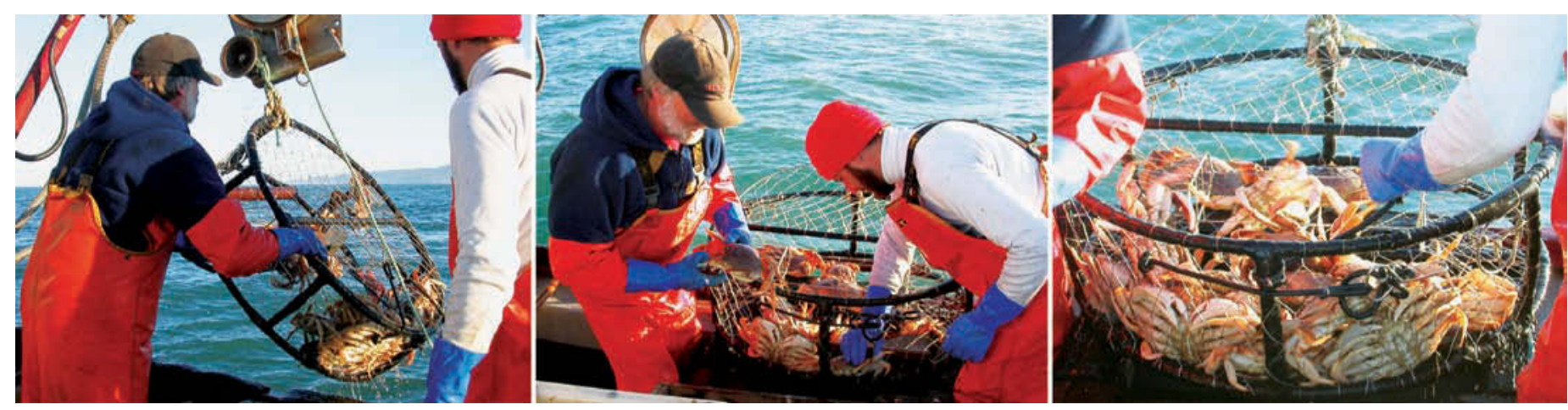

California Dungeness crab fishermen were surveyed about new management measures to distribute the catch more evenly throughout the season. The majority - except large vessel owners - support the establishment of limits on the number of traps per vessel. Commercial fisherman James Gullett and Humboldt State University student Aaron Bliesner pull traps on the Humboldt County coast.

limits may be implemented together with other restrictions such as daylightonly fishing and trap limits that differ between central and Northern California. The recently implemented buyback of trawlers (December 2003) administered by the National Marine Fisheries Service (NMFS) included 23 large vessels that also fished for crab in California (U.S. Congress 2003). Fishermen remaining in the trawl, pink shrimp and Dungeness crab fisheries will repay about $80 \%$ of the cost of this buyback to NMFS. This $27 \%$ reduction in large vessels that fish crab may change the dynamics of industry discussions about trap limits.

Quota systems. Quota systems would assign specified harvest rights for a proportion of the total allowable catch to individuals or communities. They are generally perceived unfavorably by all sectors of the crab industry. In theory and in practice, however, these harvest-rights systems create incentives that slow the race for fish and shellfish and provide opportunities for innovative marketing to add value (Casey et al. 1995; NRC 2001); both results might improve the economic performance of the fishery. With assured access to a proportion of the total catch, quota holders could time their fishing and configure their fishing operation to maximize profitability. Some processors currently are able to do this to some degree by freezing crab harvested early in the season and then processing and selling the meat during the year to meet high-value demand by restaurants (see sidebar, page 190).

Survey respondents were concerned about the potential excessive aggregation of harvest rights and difficulties in making the accurate annual crab abundance estimates needed to set individual or community quotas. If quota systems were ever implemented, these concerns would have to be addressed. In addition, individual or community quotas would have to be specified geographically to be effective.

Given the current unfavorable opinion of quota systems, they are unlikely to be considered seriously in the near future even though they would likely slow the pace of the fishery. The Pacific Fishery Management Council's fall 2003 decision to examine individual fishing quotas for the groundfish trawl fishery could influence future knowledge and attitudes about quota systems in the crab fleet. The British Columbia (Canada) groundfish trawl fishery has operated profitably in recent years under an individual quota system. This has provoked a high level of awareness and interest from the U.S. Pacific Coast trawl fleet. The council conducted public scoping meetings on trawl fishery individual quota systems during summer 2004.

Regional or zonal management. Owners of larger vessels tend to view spatial management unfavorably. Their comments indicated a desire to move freely throughout the state to take advantage of the earlier season opening in central California as well as to maintain flexibility in their operations. Some fishermen would like to see trap limits only for central California and a uniform season opening date statewide. We feel that regional differences are likely to be part of any changes in crab management because crabs are usually more abundant in Northern California and the northern vessels, on average, are larger.

Daylight-only fishing and one traphaul per day. These two management tools could be used to slow the fishery by reducing the fleet's fishing efficiency and harvest capacity. Not surprisingly, daylight-only fishing was significantly more popular with smaller vessel owners for whom night fishing is impractical and risky. Daylight-only fishing would reduce competition from large vessels that can fish many more traps, 24 hours per day, and in adverse weather conditions.

\section{Where is the fishery headed?}

This study clearly shows that the majority of the vessel owners favor some type of trap limits and some limitations on fishing at night. The larger, higher producers, who are fewer in number, tend to view further restrictions negatively, as hampering their ability to fully utilize their harvesting capacity. These decades-long differences in opinions due to vessel size continue to make management changes difficult.

The most likely near-term outcome is the adoption of some form of trap limits, at least on an experimental basis. The crab fishery in Washington recently adopted tiered trap limits and Oregon is seriously considering them. If Oregon implements trap limits, excess gear from Oregon could wind up being used in California and further intensify the fishery, pushing California toward trap limits.

Any trap-limit program should be closely evaluated after implementation. Other than preventing explosive growth in the amount of gear fished, a single level of trap limits (250 traps per vessel is proposed in current pending legislation) alone would likely have little effect on the overall fishery other than some transfer of catch from larger operations to smaller ones. As in many other common-pool natural resource 
settings, the potential for redistribution of profits serves as a potent barrier to change (Hackett 1992).

If the fishermen's goal is to reduce the total amount of gear fished significantly below the current total of approximately 170,000 traps, some plan for systematically lowering total trap numbers will be needed. Some options include:

Trap certificates. Transferable or nontransferable certificates could be used that fit under an overall statewide or regional trap total. This total could be adjusted downward in an orderly fashion over the years to reach a generally acceptable number. Setting a target trap total(s) at the beginning of the process may help fishermen to accept the program.

Vessel trap limits. Limits could be set lower each season until reaching a target level. Larger vessels would likely oppose this approach. Trap limits could be scaled to vessel size.

Buy out. Those interested in leaving the fishery would receive a monetary payment similar to the recently implemented trawl-fleet buyback through a government loan. Those remaining in the fishery would reimburse the government over time. Some restrictions on traps would be needed to prevent excessive expansion by those remaining.

Harvest-rights system. Transferable or nontransferable rights would allocate a proportion of the overall allowable catch to each fisherman. This could slow the race for crabs and provide incentives for fishermen to make their individual businesses more efficient. It would require improved estimates of crab abundance, improved enforcement, quotas within geographic zones and agreed-upon quota aggregation limits.

Status quo. Let attrition under the current restricted-access program gradually reduce fleet size and perhaps the number of traps fished. This would likely take many years.

Trap limits appear to be the only alternative with a likelihood of adoption in the near term, but the long-term consequences of that approach are unclear.

Why haven't management tools used elsewhere in the world been seriously considered in California? It could be because trap limits have been considered and debated in great depth for many years. Fishermen, processors, DFG staff and key legislators have high awareness and knowledge about this approach compared to other alternatives.

Rogers (1995), in summarizing the large body of research about the adoption of new technologies and practices, demonstrates that people go through a series of stages in their process of adoption or rejection. Crab fishery participants are clearly well along in this process for trap limits and have developed perceptions of their relative advantages or disadvantages. However, many of these same participants have not been as focused on alternative management tools and are not as far along in the adoption/rejection process for them.

In addition, the California legislature - rather than the Pacific Fishery Management Council, DFG or the Fish and Game Commission - has primary responsibility for policy related to the Dungeness crab fishery. (The U.S. Congress transferred this authority to the individual state legislatures in 1996.) The long-term lack of industry consensus has made management changes by the legislature difficult in the past and is a likely barrier to alternative management approaches in the future, with the possible exception of some form of trap limits. If trap limits are adopted in the near future, but do little to solve perceived problems in the fishery, then it is possible that industry, fishery managers and the legislature will focus their attention on additional management options.

C.M. Dewees is Sea Grant Marine Fisheries Specialist, and K. Sortais is Research Associate, Department of Wildlife, Fish and Conservation Biology, UC Davis; M.J. Krachey is Graduate Student, and S.C. Hackett is Professor, Department of Economics, Humboldt State University; and D.G. Hankin is Professor, Department of Fisheries, Humboldt State University. The authors acknowledge the 243 crab fishermen who generously shared their opinions and information about their business operations. We thank George Boos, Jack Carlson, Peter Leipzig, Chuck Wise and Richard Young for helping to set up project focus-group meetings and workshops in fishing ports.
Thanks also to Janelle Kohl, California Sea Grant Extension Program, for her assistance with editing and layout. This research was supported in part by the National Sea Grant College Program of the U.S. Department of Commerce's National Oceanic and Atmospheric Administration under NOAA Grant \#NA06RG0142, project \#R/F-187, through the California Sea Grant College Program, and in part by the California State Resources Agency. The views expressed herein do not necessarily reflect the views of any of those organizations.

\section{References}

Acheson JM. 2001. Confounding the goals of management: Response of the Maine lobster industry to a trap limit. N Am J Fisheries Mgmt 21(2):404-16.

Casey KE, Dewees CM, Turris BR, Wilen JE. 1995. The effects of individual vessel quotas in the British Columbia halibut fishery. Marine Resource Econ 10(3):211-30.

[CFAC] Coastal Fisheries Advisory Commission. 1997. Georgia Blue Crab Fishery Management Plan. Blue Crab Issues Subcommittee. Georgia Department of Natural Resources. Brunswick, GA.

Didier AJ. 2002. The Pacific Coast Dungeness Crab Fishery. Pacific States Marine Fisheries Commission, Gladstone, OR. $30 \mathrm{p}$.

Dillman DA. 2000. Mail and Internet Surveys: The Tailored Design Method (2nd ed.). New York: J Wiley. 464 p.

Hackett SC. 1992. Heterogeneity and the provision of governance for common-pool resources. J Theoretic Politics 4(3):325-42.

Hankin DG, Warner RW. 2001. Dungeness crab. In: Leet WS, Dewees CM, Klingbeil R, Larson EJ (eds.). California's Living Marine Resources: A Status Report. Sacramento: California Dept. of Fish and Game. UC DANR Pub SG01-11. p 107-11.

Hays HL. 1988. Statistics (4th ed.). Orlando, FL: Holt Rinehart Winston. 1,029 p.

Larken SL, Milon JW. 2000. Tradable effort permits: A case study of the Florida spiny lobster trap certificate program. In: Proc Tenth Biennial Conf Int Inst Fisheries Econ Trade. http://oregonstate.edu/Dept/IIFET/2000/ papers/larkin.pdf

Leet W, Dewees C, Haugen C. 1992. California's Living Marine Resources and their Utilization. California Sea Grant Extension Pub UCSGEP-92-12. Davis, CA. 257 p. Manly BFJ. 1997. Randomization, Bootstrap, and Monte Carlo Methods in Biology (2nd ed.). London: Chapman Hall. 399 p. [NRC] National Research Council. 1999. Sharing the Fish: Toward a National Policy on Individual Fishing Quotas. Washington, DC: Nat Acad Pr. 422 p.

[PSMFC] Pacific States Marine Fisheries Commission. 1993. A review of the California, Oregon and Washington Dungeness crab fishery. Gladstone, OR.

Rogers EM. 1995. Diffusion of Innovations (4th ed.). New York: Free Pr. 519 p.

US Congress. 2003 (Nov. 4). Fed Reg 68(213):62435-8. 